\title{
REPRESENTAÇÕES GRÁFICAS NO ENSINO DE GEOGRAFIA: UM AUXÍLIO À EDUCAÇÃO AMBIENTAL NOS ANOS INICIAIS
}

\section{Graphic representations in geographical education: a contribution to environmental education in elementary school}

\author{
Carolina Oliveira de Andrade Lemos \\ UERJ - Faculdade de Educação da Baixada Fluminense \\ carolinaodal.geo@gmail.com \\ Thaís Oliveira Marques \\ UERJ - Faculdade de Educação da Baixada Fluminense \\ th4is.oliveira@gmail.com
}

Artigo recebido em 22/08/2017 e aceito para publicação em 03/10/2017

DOI: $10.12957 /$ tamoios.2017.30082

\begin{abstract}
Resumo
Dialogando o Ensino de Geografia com a Pedagogia do primeiro ciclo do Ensino Fundamental, este artigo resgata alguns fundamentos didáticos do desenho pela possibilidade de elucidar conceitos e conteúdos da Educação Ambiental como tema transversal nos anos iniciais e a capacidade de interpretação do professor acerca das representações gráficas realizadas por crianças do $2^{\circ}$ ano do fundamental do CAp UERJ. Ao considerar a contextualização das práticas de ensino com o espaço vivido dos alunos, discute o papel do desenho a partir do exemplo do auxílio à Educação Ambiental e sugerimos ferramentas metodológicas que nos ajudem a descobrir o que se esconde sob os desenhos. Além de constituir um conjunto de saberes para transformar as informações obtidas nos desenhos em situações consequentes para novas propostas em sala de aula.
\end{abstract}

Palavras-chave: representações gráficas; ensino de geografia; ensino fundamental; metodologia; educação ambiental.

\begin{abstract}
The dialogue the geography teaching with the pedagogy of the first cycle of Elementary Education allowed this article seeking to recover the didactic fundamentals of the drawing to elucidate concepts and contents of Environmental Education as a cross - cutting theme in the initial years and the teacher 's ability to interpret the graphic representations made by Children of the 2nd year of the fundamental of CAp UERJ. That when considering the contextualization of teaching practices with the lived space of the students, it discusses the role of the drawing for the aid to Environmental Education and outlines methodological tools that help to discover what is hidden under the drawings. Besides constituting a set of knowledges to transform the information obtained in the drawings into situations consequent to new proposals in the classroom.
\end{abstract}

Keywords: graphic representations; geography teaching; elementary school; methodology; environmental education. 


\section{INTRODUÇÃO}

Ao trabalhar com uma educação comprometida com a realidade desde os anos iniciais é preciso conceber situações didáticas (PERRENOUD, 2000) vinculadas com mundo próximo das crianças para que elas possam desenvolver seu processo cognitivo ${ }^{1}$ com maior espontaneidade e tenham um bom envolvimento com as práticas educativas propostas para elas durante as atividades pedagógica sala de aula. Porém, a concepção dessas situações pode configurar-se num grande desafio frente às condições da relação de ensino-aprendizagem dispostas. E dentre os desafios, o qual nos referimos neste trabalho, é o de propor para as turmas dos anos iniciais atividades como a elaboração de representações gráficas dos assuntos relacionados à Educação Ambiental, em diferenciar através delas as representações mentais, espaciais e sociais realizadas pelas crianças (PONTUSCHKA et al., 2007). Para então descobrirmos: o que se esconde sob os desenhos? Cabe ao aluno desenhar e o professor interpretar? Como trabalhar em cima das descobertas?

A partir dessas questões, buscamos por respostas analisando atividades no $2^{\circ}$ ano do fundamental I do Colégio de Aplicação da Universidade do Estado do Rio de Janeiro (CAp-UERJ). Tais atividades observadas por apenas uma das autoras, revelam que maioria dos alunos sentem-se desafiados ao representar graficamente. Como se tivessem num confronto entre o mundo próximo e mundo imaginário. Enormes são as pistas e dados revelados da vida de cada criança estruturando uma complexidade das diferentes realidades vividas. Sendo assim, os registros gráficos tornam-se não só um desafio para as crianças, mas para o professor da turma em tentar compreender aquilo que foi reproduzido por cada um.

A metodologia, portanto, deve explorar o desenvolvimento de práticas a fim de recuperar as significações do desenho infantil (PEREIRA, s.d.) e transformá-las em ocasiões para auxiliar a compreensão da Educação Ambiental (CALLAI, 2014) ao constituir novos saberes didáticos pela interdisciplinaridade do Ensino de Geografia. ${ }^{2}$ Logo, a tríplice função apresentada por Callai (2001), como o resgate do conhecimento científico, a valorização do conhecimento das crianças e a atribuição de um sentido social sobre os conteúdos representados, pode ajudar no desenvolvimento desta pesquisa.

Assim, a apresentação deste trabalho inicia-se discutindo o papel do desenho no Ensino de Geografia como recurso metodológico, depois segue para a defesa do desenho sendo uma prática pedagógica alternativa para a Educação Ambiental, justificando-se a partir da descrição de um episódio realizado durante um projeto, acarretando na necessidade de uma breve apresentação do mesmo. Discorre sobre a transdisciplinaridade e interdisciplinaridade da Educação Ambiental como um canal que contribui na inserção do Ensino de Geografia nos anos inicias.

Apresenta uma abordagem metodológica do desenho pela interlocução entre autores que desenvolvem a temática e também sobre a relevância da contextualização nas atividades realizadas em sala de aula, em defesa do comprometimento da educação com a realidade. E prossegue esboçando ferramentas metodológicas que auxiliam na descoberta do que os desenhos podem desvendar ao serem utilizados para elucidar conceitos e conteúdos da Educação Ambiental. Ao encerrar, propõe transformar as sínteses gráficas dos alunos em novas ocasiões para aplicar os novos saberes constituídos. 


\section{O DESENHO NO ENSINO DE GEOGRAFIA}

Geralmente, quando pensamos em representações gráficas no Ensino de Geografia, pensamos em representações cartográficas. Pois a cartografia é um importante objeto de estudo para a geografia. Através dela, pela sua função comunicadora, podemos encontrar auxílios para desvendar o espaço. A cartografia procura representar o espaço geográfico em distintas finalidades, mas ela destina-se, prioritariamente, a representar a superfície terrestre. Segundo, Lívia de Oliveira (2014):

"O mapa ocupa um lugar de destaque na Geografia, porque é ao mesmo tempo instrumento de trabalho, registro e armazenamento de informação, além de um modo de expressão e comunicação, uma linguagem gráfica" (p.16)

E o desenho é uma alternativa de linguagem gráfica que vinculado ao Ensino de Geografia assume uma proximidade com a função cartográfica, no que se refere apreender e compreender o espaço. Por esse motivo, recorremos brevemente aos estudos metodológicos e cognitivos dos mapas (OLIVEIRA, 2014) a fim de obter suporte teórico para esboçar uma abordagem didática da representação gráfica nessa área de estudo, porque assim como os mapas, os desenhos também comunicam. Eles "falam" e geram uma "escuta" (OLIVEIRA Jr., 2011). De tal maneira, podemos analisálos pelos fundamentos psicológicos e geográficos encontrados nos estudos dos mapas realizado por Oliveira (2014). Fundamentos que vão surgindo no desenvolvimento intelectual do lugar, este como possível de ser apreendido pela memória através do sentido dos corpos ${ }^{3}$, desde as primeiras relações espaciais realizadas pelas crianças.

O desenho como prática no Ensino de Geografia é readmitido enquanto método que permite reconhecer o processo cognitivo dos alunos, mas vai além. Sabe-se que através dele as crianças são desafiadas a construir traços de referências com enormes revelações dos valores que cada indivíduo toma para si dos lugares ou fenômenos e processos espaciais diferentes (PONTUSCHKA et al., 2007). Com isso, podemos aproveitar a contribuição de Oliveira (2014) e adequá-la para encarar os desenhos como abordagem metodológica e cognitiva, assim como os mapas, e esboçar uma metodologia que nos ajude a desvendar o que se esconde sob eles.

Logo, falaremos daqui pra frente do uso de uma linguagem habitual na alfabetização. Da representação gráfica realizada com canetinhas coloridas e papel nos anos iniciais e não necessariamente de mapas. Discutiremos o desenho infantil pela sua função de atribuição da significação que se expressa e se constrói desde o início do seu desenvolvimento (PEREIRA, s.d.). Porém, agregaremos a perspectiva geográfica, ela, interessada em atribuir à significação uma leitura espacial, acompanhada dos aspectos mentais e sociais das crianças. Onde a representação gráfica consiste como recurso de apreensão e compreensão da organização do espaço (PONTUSCHKA et al., 2007).

Todavia, apesar deste artigo está fundamentado numa experiência de alfabetização, ou seja, nas séries iniciais do Ensino Fundamental, esse uso de linguagem através das representações gráficas para o Ensino de Geografia não está isolado ao nível de escolarização explicitado. Essa abordagem em discussão e os conhecimentos próprios dela pressupõem que esta prática seja contínua e cumulativa, portanto poderá ser estendida aos demais anos de escolarização, principalmente para apresentar e trabalhar os demais conceitos geográficos. Para isso, o educador, deve utilizar-se do discernimento e de critérios para realizar devidas adaptações e abstrações necessárias de acordo com a etarização das turmas nas séries mais avançadas. 
O desenho, segundo Pereira (s.d.), subordina-se às leis da conceituação e da percepção. E o que predomina nele é a assimilação ${ }^{4}$. Neste caso, a projeção e operação executada nos desenhos infantis vão além do que lhe é proposto em sala de aula. As crianças costumam buscar referências no meio externo a escola e carregam em suas bagagens uma realidade material que é confrontada com a realidade conceituada e nesse impasse necessário desenvolvem as representações a partir de suas assimilações. O que implica relevar a representação gráfica não como uma generalização, identificada por Pereira (s.d.), mas, sim, como síntese. Isto porque não devemos encará-la como resultado de uma ação ou simplificação da significação da criança no desenho, mas examiná-la enquanto síntese por dar-se ou constituir-se como novas propostas a partir dos dados referenciados nos registros infantis. A assimilação não expressa totalidade, por isso não pode ser lida enquanto afirmação. Ela materializa-se pela presença e ausência de memórias, portanto, firma-se como fragmento da realidade vivida pelo aluno ou como revelação do mundo próximo, mas nem tão próximo assim.

É preciso identificar as potencialidades dessa atividade e quais subsídios disponibiliza para auxiliar os alunos à uma Educação Ambiental enquanto tema transversal do Ensino de Geografia. Investigar como as crianças constroem as representações (OLIVEIRA, 2014) inicia uma abordagem metodológica do desenho, que aliado ao olhar geográfico torna-se um importante recurso visual estimulador do senso crítico e desenvolvedor de capacidade de contextualização, interpretação e análise do aluno (OLIVEIRA Jr., 2011).

\section{O DESENHO PELA EDUCAÇÃo AMBIENTAL COMO PRÁtica ALTERNATIVA}

O uso do desenho nos anos iniciais é uma prática comum. Muitos professores utilizam-se da didática que o concerne para o ensino/aprendizagem nas aulas. Mas quando ele é proposto como atividade de representação gráfica sob a perspectiva do Ensino de Geografia temos uma alteração em sua finalidade prática. Se antes essa linguagem gráfica era utilizada pela preocupação do desenvolvimento cognitivo do aluno, agora ela ainda continua com essa preocupação, no entanto, tende-se a preocupar também com o reconhecimento das relações espaciais infantis.

Essa verificação foi proporcionada pelo projeto de iniciação à docência da qual uma de nós fez parte entre os anos de 2015 e 2017. Nele pesquisamos, direta e indiretamente, como constituir saberes didáticos para lidar com a diferença na escola investigando as manifestações das diferenças, ancoradas nos aspectos da diversidade racial, cultural, econômica, de gênero, física ou de outra ordem nas turmas do Fundamental I no Colégio de Aplicação da Universidade do Estado do Rio de Janeiro. Com a finalidade de socializar as discussões acerca do desenvolvimento de novas didáticas.

O projeto é uma realização do grupo de pesquisa "Formação em Diálogo: Narrativas de Professoras, Currículos e Culturas" e está inserido no contexto do Ensino Fundamental I, onde as professoras pedagogas que compõem o projeto atuam, porém, apesar do campo de atuação, ele não se faz restrito apenas aos licenciandos da pedagogia, estudantes de outras licenciaturas também são admitidos. Essa abertura para outras áreas do ensino colabora para a interdisciplinaridade dos saberes a serem constituídos, pois cada licenciando poderá ajudar desenvolvê-los relacionando-os com a própria prática de sua formação. Dessa forma, enquanto estudante de geografia, a atenção com as práticas relacionadas aos temas abordados pela ciência geográfica é privilegiada. Partindo desse interesse, é importante mencionar o que foi verificado em 
sala de aula em cima dos estudos sobre a representação gráfica e espacialidade em conformidade com objetivo do projeto de identificar as manifestações das diferenças pela desigualdade socioespacial entre as crianças da turma. De uma eventualidade específica durante a rotina escolar deu origem a pesquisa.

Certa vez, um aluno, inesperadamente, questionou a professora da turma se no Japão e na China as pessoas compartilham do mesmo idioma. Na tentativa de responder a curiosidade da criança, a professora recorre ao mapa estendido no mural da sala para indicar, geograficamente, os países em questão. Não era um mapa elaborado para crianças, pois tratava-se de um mapa para adultos, ainda sim deixou de ser atrativo para elas. Conforme íamos tentando responder a primeira pergunta, muitas outras surgiam enquanto as crianças faziam a leitura cartográfica daquele mesmo mapa. Percebemos que naquele momento foi instaurada uma nova situação didática que foi ao encontro da afirmativa de Oliveira (2014), quando diz que é em "sala de aula que se pode começar a investigar experimentalmente como as crianças manipulam os mapas". A professora logo se convenceu de que era conveniente à aprendizagem o estudo pelo mapa naquele momento. Daí, nesse novo arranjo das situações didáticas, a primeira decisão foi deixálos observar a comunicação cartográfica e elaborar livrementes curiosidades acerca da representação espacial.

Desde o estranhamento das abstrações representadas até o levantamento de hipóteses do que poderia está sendo representado, as crianças buscavam compreender as informações trazidas pelo mapa. E não demorou muito para as tais linhas vermelhas que representavam os limites da distribuição das placas tectônicas tornassem destaque. "Elas realmente existem no mar?", perguntavam indicando uma mudança substancial do assunto preliminar. Diante disso, vimos a dificuldade que é abordar conteúdos da geografia nos anos iniciais. Enquanto o docente de geografia enfrenta a ausência de práticas de ensino para o primeiro ciclo da educação formal, a professora pedagoga enfrenta faltas de recursos epistemológicos oriundos da Geografia que auxiliem sua prática - discutiremos isto mais adiante. Além da limitação de outros recursos, como por exemplo, o material didático. Haja vista, o tipo de mapa disponível em sala de aula.

Contudo, são ausências que não nos impediram, apesar das dificuldades, encarar o prosseguimento pedagógico da situação naquele momento. Pois, em conjunto, procuramos abordar os conteúdos relacionados e discutir, numa perspectiva geográfica, os fenômenos naturais provocados pelo deslocamento de placas. Daí então atestamos que a flexibilidade dos temas e conteúdos a serem ensinados pode corresponder uma aprendizagem espontânea. Mas como podemos avaliar o alcance dessa aprendizagem proporcionada por um planejamento didático flexível? Como verificar se é válido aproveitar ocasiões partindo dos interesses dos alunos?

Bem, dentre outras formas possíveis de avaliações, a professora optou pela elucidação dos conceitos através da representação gráfica. Propôs, então, à turma desenhar os fenômenos discutidos acerca da dinâmica de placas tectônicas. Essa proposta veio a ser a atividade incentivadora desta pesquisa, pois foi o feedback do ensino a partir do sistema de representações das crianças. Das funções que utilizaram para explicar suas apreensões e assim nos permitir acessos de compreensão do desenvolvimento cognitivo do aluno e suas relações espaciais com o mundo externo.

É desafiante abordar fenômenos referentes aos efeitos da dinâmica das placas tectônicas como terremoto, tsunami e surgimento de vulcões e cadeias montanhosas no $2^{\circ}$ ano do fundamental. Até porque, essa abordagem não é exigida nos anos iniciais. Paisagens locais e espaços vividos são as referências priorizadas no Ensino Fundamental I (CARLOS, 2007). ${ }^{5} \mathrm{E}$ alguns desses fenômenos não implicam diretamente no cotidiano e contexto geográfico das crianças em questão. Mas ainda sim 
criamos expectativas das apreensões dos alunos e procuramos não subestimá-los. Afinal, o interesse era partilhado entres eles.

Dessa forma, na verificação da elucidação dos conteúdos abordados, encontramos o desenho que nos instigou a descobrir o que se esconde sob ele. Em como interpretá-lo e, sobretudo, como trabalhar em cima das suas representações. Esse desenho foi realizado por uma criança de 7 anos que representou um tsunami e acrescentou na imagem pessoas surfando sobre a onda. Até aí, nenhum motivo de contestação, senão pelo motivo de não ser uma onda comum de superfície, mas sim um fenômeno natural, violento quando geográfico, que impossibilitaria atividades humanas sobre ele. Entendemos que essa representação apresenta normalidade, pois como Pereira (s.d.) sinalizou, o desenho subordina-se a lei da conceituação e percepção, logo há o predomínio da assimilação. Pois as referências externas permitem relacionar ondas do mar com esportes feito o surf. Porém, a finalidade de elucidar os conteúdos exigiu uma intervenção para explicitar consequências ambientais do tsunami acarretando na impossibilidade de atividades e interações humanas simultaneamente ao seu acontecimento.

Entretanto, o aluno insistiu em representar pessoas surfando no tsunami, revelando o confronto entre a realidade material e realidade conceituada. Nesse momento deparamo-nos com um obstáculo à aprendizagem que deveria ser superado. Então, surgiu o interesse em descobrir se poderíamos estar enfrentando algo além da assimilação que identificamos préviamente.

Tomando conhecimento de que a assimilação não é uma afirmação, levantamos hipóteses interpretativas para novas descobertas. Para isso, nos apoiamos nas raízes do aluno, procurando contextualizar sua realidade vivida através do seu histórico e registros anteriores. Considerando dados e pistas, pensamos ser, a representação, um reflexo de sua experiência socioespacial do lugar onde mora. Bairro de Benfica localizado no subúrbio da cidade do Rio de Janeiro. Um lugar de baixa renda populacional com serviços urbanos precários proporcionados pelo (des)interesse administrativo da cidade. Que obriga a comunidade conviver com problemas ambientais urbanos cotidianamente, portanto, sem alternativas de evitar interagir com situações que os oferecem riscos.

Nesse aspecto, cravamos a questão: representações gráficas do aluno, interpretações do professor? Seria responsável agregar este valor e sentido social ao desenho sem maiores investigações? Isto é o que tentamos responder desde quando nos propusemos questionar nossa prática. Tomando como exemplo a situação descrita acima, discutiremos a respeito da Educação Ambiental por sê-la pertinente à contribuição do Ensino de Geografia nos anos iniciais e por enredar assuntos relacionados com a problemática levantada desde risco e vulnerabilidade ambiental até a justiça social para exercício à cidadania.

\section{EDUCAÇÃO AMBIENTAL CONTRIBUINDO PARA O ENSINO DE GEOGRAFIA NOS ANOS INICIAS}

A Educação Ambiental, segundo Sene (2011), foi impulsionada a partir das preocupações com a questão ambiental discutidas na década de 1970 com eventos voltados ao enfrentamento da crise ambiental que havia sido instaurada desde a ofensiva global de extração de recursos naturais em nome do desenvolvimento econômico. De uma importância universal, a Educação Ambiental tem alguns objetivos que justificam sua relevância pedagógica no planeta. Esses objetivos estão descritos numa estrutura 
global de Educação Ambiental, conhecida como Carta de Belgrado, também citada por Sene (2011).

Nela há dois objetivos preliminares: a pretensão de elucidar o significado dos conceitos básicos como a "qualidade de vida", por exemplo e, também, incentivar a identificação de ações que favoreçam o bem estar da sociedade. Essas são as metas preliminares que visa melhoria das relações ecológicas globais. Outro objetivo mais específico descrito na carta e que precisa da intervenção pedagógica, formal ou informal, é a conscientização da população dos problemas ambientais com o desenvolvimento de atividades que incentive o comprometimento do trabalho individual e coletivo a favor do meio ambiente.

Nesse horizonte, algumas diretrizes universais são estabelecidas para serem aplicadas e contextualizadas conforme os diferentes países, estados, municípios e bairros trabalhados. Embora tenhamos recortes espaciais de atuação com necessidades ambientais específicas, a Educação Ambiental nos oferece, pela estrutura global, subsídios para atuarmos em diferentes escalas geográficas. Contudo, não podemos desconsiderar a totalidade ecológica, cultural, econômica e social das comunidades. Uma abordagem relacional é a chave mestra para encararmos as questões ambientais atuais.

Por isso, devemos relacionar as necessidades ambientais brasileiras de conscientização com a necessidade internacional de preservação ao meio ambiente. Focalizar o contexto brasileiro e mais ainda nas desigualdades que são enfatizadas pela política deste país. A partir disso, saber o que o Brasil espera da Educação Ambiental e como pretende fazê-la. Nesta busca, vimos que para Sene (2011), o que fica evidente na expectativa da sociedade brasileira é a Educação Ambiental cooperando para um desenvolvimento sustentável através dos princípios básicos enunciados na lei $\mathrm{n}$. 9.795/99. Onde a concepção do meio ambiente seja simultaneamente compreendida enquanto natural e social e analisada sob perspectiva da sustentabilidade (SENE, 2011).

E que apesar de ser destinada ao público nos setores formais e informais da educação, ela deve ocupar um espaço privilegiado na escola básica. Aproveitando que no Brasil a Educação Ambiental é um campo educativo que tem sido "fertilizado transversalmente" (JACOBI, 2003) pelos parâmetros curriculares nacionais. E está cada vez mais adentrando, inclusive, nos anos iniciais, partirmos das discussões em escala global, dos problemas ambientais e da necessidade de preservação e recuperação do meio ambiente promovidos pelas conferências e encontros internacionais, como a Rio 92, por exemplo, para o ensino da Educação Ambiental no Brasil à exercicio da Lei n. 9.795/99, incorporada nos Parâmetros Curriculares Nacionais como tema transversal (LEMOS; DAVID, 2011).

Os Parâmetros Curriculares Nacionais são pautados em três conceitos para o ensino da Educação Ambiental: meio ambiente, sustentabilidade e diversidade, devendo ser abordado em todas as disciplinas escolares. É um tema bastante flexível e presente em todos os ramos do conhecimento (LEMOS; DAVID, 2011). A Educação Ambiental nasce, em contexto brasileiro, como meio de esclarecer para crianças e adultos a necessidade da preservação do meio ambiente. Portanto, a escola enquanto potencialmente capaz de aplicar tais esclarecimentos através de seus recursos pedagógicos, ou como pólo das atividades pedagógicas interdisciplinares, é, mais uma vez, um espaço privilegiado para discutirmos os conceitos de meio ambiente, sustentabilidade e diversidade, mencionados anteriormente.

Ao almejá-los, contribuímos para uma cidadania de justiça ambiental, na medida em que a Educação Ambiental, promove a conscientização de uma vida digna e em um ambiente saudável para todos. Através de seus pilares, essa educação procura expandir 
as noções de qualidade de vida dos alunos, mostrando para eles a possibilidade de acesso a um ambiente salubre tanto de moradia quanto de lazer. Nela exploramos os meios necessários à vida pela compreensão de que são um direito de todos.

E em sala de aula, tendemos inserir essa conscientização pela transversalidade a partir dos assuntos plausíveis de serem abordados pelos objetivos da Lei n. 9795/99. Por isso, é bastante comum dialogar com disciplinas correspondentes. E dentre as existentes, há a Geografia, onde Sene (2011) destaca sua semelhança com a educação ambiental, pois ambas estudam, fundamentalmente, a relação sociedade-natureza.

É claro que conceitos geográficos são abordados nos anos iniciais, entretanto o Ensino de Geografia tem uma exclusividade a partir do $6^{\circ}$ ano do Ensino Fundamental. Mas não devemos ignorar o esforço e competência dos professores pedagogos em trazer aos alunos do Ensino Fundamental I a Geografia para a sala de aula. E desse modo, entendemos aqui que a Educação Ambiental contribui para a inserção da Geografia, neste primeiro ciclo, pois ambas se cruzam e se complementam. Inclusive os Parâmetros Curriculares Nacionais apresentam e propõem que essa relação seja utilizada e explorada pelos professores.

No Ensino de Geografia, a Educação Ambiental contribui na elucidação dos temas e conceitos geográficos. E no ensino/aprendizagem das situações pedagógicas dos anos iniciais, a Educação Ambiental é uma excelente oportunidade de adentrar os conceitos relativos ao espaço geográfico onde "paisagem" e "lugar" tem enorme validade nas discussões com as crianças. Logo, teríamos o educador enquanto mediador desse resgate de referenciais entre uma disciplina e outra na construção de um quadro socioambiental que não autonomiza os fenômenos imediatos do cotidiano vivido das crianças, mas que se compromete com a interrelações entre o meio natural e social que elas desenvolvem suas práticas sociais.

É importante salientar que não tivemos a intenção de trabalhar a respeito da Educação Ambiental como um objeto de estudo deste artigo, apenas como um exemplo de abordagem metodológica do desenho. A necessidade de trazê-la "à tona", foi pela situação descrita do episódio que nos fez interessar pela representação gráfica no Ensino de Geografia por ter levantado questões de vulnerabilidade ambiental. Este tópico cumpre em apresentar a Educação Ambiental no contexto pedagógico brasileiro de maneira bem breve, por sua relação e contribuição mútua com o Ensino de Geografia. E como potencialidade de abarcar as problemáticas surgidas.

\section{ABORDAGEM METODOLÓGICA DO DESENHO}

Acreditamos que considerar uma abordagem metodológica do desenho nos encaminhará a encontrar métodos para a descoberta das revelações possíveis das representações gráficas realizadas pelas crianças. Para isso, partiremos de três princípios indispensáveis para o desenvolvimento de capacidades de interpretação: o reconhecimento de que a criança é o primeiro intérprete da representação (PEREIRA, s.d.), considerar os desenhos como síntese daquilo que puderam compreender e exercício de diferenciação da imagem representada nos aspectos mentais, sociais e espaciais (PONTUSCHKA et al., 2007).

Mas antes de discorrer sobre esses princípios, devemos questionar a ação interpretativa do professor. Cabe ao educador a interpretação do desenho do aluno? De certa forma sim, pois para orientá-los é preciso, antes, identificar as pistas dadas por eles durante as atividades. Porém, a pergunta reside no aspecto de interrogar se essa interpretação pode ser absoluta, independentemente dos critérios docentes utilizados para decidir o que remete a representação gráfica da criança. 
Se admitirmos que a interpretação é absoluta, automaticamente estaremos enaltecendo a precipitação e reducionismo da avaliação docente. E que os desenhos não precisam ser vistos como abordagem metodológica, porque nele não se obtém descobertas já que através dele é possível inferir os resultados da prática. Mas admite-se aqui que essa interpretação é condicional, ou seja, ela depende de alguns princípios que nos encaminham para descobertas ao invés de decisões precipitadas. Muito tem a ver com o papel do professor-investigador com sua "atitude de estar na profissão como intelectual que criticamente questiona e se questiona" (ALARCÃO, 2001). Que pretende compreender as limitações de sua prática e promove soluções para serem compartilhadas e discutidas com outros docentes.

Ainda antes de retomar aos princípios de interpretação para descobrir o que os desenhos escondem, é pertinente falar do acompanhamento imediato da produção do desenho após a proposta. Para participar do processo de elucidação deve-se estar atento às construções iniciais das crianças (PEREIRA, s.d), pois nada impede o surgimento de pistas ainda no desenvolvimento do desenho. A partir desse acompanhamento a aplicação dos princípios de capacitação para interpretar, ou melhor, desvendar significações do espaço vivido e das práticas sociais experimentadas pelas crianças pode ser realizada sem maiores advertências.

Primeiramente, pelas interações, incentivar as crianças narrar aquilo que representam. Reconhecer que os aprendizes são os primeiros intérpretes dos desenhos (PEREIRA, s.d.) e os únicos a transpor fielmente os significados das representações. É que, embora os desenhos possam revelar manifestações não ditas, as falas devem ser valorizadas para posteriormente serem recontextualizadas. Através da oralidade capturar informações e relacioná-las com a imagem produzida.

Pereira (s.d) considera que a linguagem verbal é a base da linguagem gráfica, destaca, através de Vygotsky (1988, apud PEREIRA, s.d.), que o momento fundamental do desenho é constituído anteriormente a ação gráfica, pela manifestação verbalizada, que é a intenção prévia da representação. Atentar-se nas falas das crianças, portanto, é um princípio que antecede outras capacidades de interpretação. Principalmente quando há a compreensão de que a oralidade está atrelada à construção do desenho não somente na sua fase inicial, mas em todo processo e desempenho de funções para sintetizar as representações gráficas.

Por conseguinte, considerar os desenhos como síntese daquilo que puderam compreender durante as atividades. Admiti-los como consequência das assimilações das crianças entre a realidade material e realidade conceituada. Longe de ser uma generalização, mas algo muito próximo de vir à ser novas propostas pedagógicas pelas presenças e até ausências de referenciais que possam ser futuramente trabalhados.

A significação da criança, aquilo que ela indica pela representação gráfica, não pode ser totalmente apreendida pelo professor, há limitações que impedem sua totalidade. $\mathrm{O}$ caráter assimilatório nem sempre atende a demanda de referenciais que a criança recebe. Entretanto, a representação gráfica viabiliza a construção e a expressão da significação infantil (PEREIRA, s.d.), pois as funções utilizadas nesse processo dá estímulos a essa construção. Que ao produzir e revelar-se enquanto síntese das relações operacionalizadas, entre as três diferentes dimensões: mentais, sociais e espaciais (PONTUSCHKA et al., 2007), constitui-se como consequente às assimilações e permite avaliar a elucidação através da imagem.

Em falar dessas três dimensões operacionais, elas formam o terceiro princípio para a interpretação docente e desempenham diferentes funções que precisam ser individualmente identificadas embora sejam interdependentes e correlacionadas. Essas operações contribuem e dão características significativa ao desenho e a partir delas 
conseguimos encontrar dados do espaço vivido, das práticas sociais e os elementos de análise sobre o desenvolvimento cognitivo dos alunos (PONTUSCHKA et al., 2007). Logo, ao exercitar a diferenciação entre essas três dimensões tendemos a organizar melhor os critérios docentes da interpretação e leitura da imagem. Assim, terminamos de apresentar o conjunto de princípios que consideramos indispensáveis a aprimoração da capacidade de interpretação do professor sobre os desenhos elaborados em aula.

\section{A IMPORTÂNCIA DA CONTEXTUALIZAÇÃO AO PROPOR REPRESENTAÇÕES GRÁFICAS}

$\mathrm{Na}$ área da educação diversos educadores presenciam a falta de envolvimento dos alunos com as práticas educativas propostas em sala de aula. Porém, sabe-se que ao reverter essa contradição realizamos um importante e considerável passo para prosseguir as metodologias de ensino pretendidas, pois, a partir do envolvimento dos alunos com as práticas em sala de aula, maior é a possibilidade de participação e colaboração do corpo discente na relação ensino/aprendizagem.

Discutiremos a respeito de uma educação comprometida com a realidade. Acredita-se, aqui, que através (e somente) dela alcançamos bons resultados para sanar a alienação dos alunos, porém não só deles, mas também dos professores em relação às práticas educativas e o comprometimento com a realidade do conjunto escolar. Priorizando uma participação em defesa da qualidade de vida pela Educação Ambiental (JACOBI, 2003).

Para isso, nos apoiamos em Perrenoud (2000), na tentativa de justificar a importância da contextualização no ensino. Destacando a objetividade para a Educação Ambiental e assim, elaborar possíveis respostas, se nos propusermos a questionar qual seria o melhor caminho para envolver as crianças com as práticas educativas apresentadas em sala de aula. Esse modo de pensar atende ao compromisso de considerar a realidade como elemento fundamental para o ensino à cidadania. Mas de que cidadania estamos falando? Àquela que para Jacobi (2003):

“[...] tem a ver com a identidade e o pertencimento a uma coletividade. A educação ambiental como formação e exercício de cidadania refere-se uma nova forma de encarar a relação do homem com a natureza, baseada numa nova ética, que pressupõe outros valores morais e uma forma diferente de ver o mundo e os homens [...] deve ser vista como um processo de permanente permanente aprendizagem que valoriza as diversas formas de conhecimento e forma cidadãos com consciência local e planetária.” (p. 198)

Bem, ainda que os propósitos pautados no parágrafo anterior apareçam individualizados, como a justificativa da importância da contextualização e a busca por respostas que colaborem na maior disposição de envolvimento dos alunos com as práticas pedagógicas, eles são interdependentes. Ora pelas justificativas, que se materializam na busca pelo envolvimento das crianças com as práticas, ora pelo envolvimento delas que só se concretiza pelo exercício de contextualização.

Perrenoud (2000) em suas orientações de como "organizar e dirigir situações de aprendizagem", defende a concepção de situações didáticas vinculadas ao mundo próximo das crianças. Para que assim elas possam desenvolver seu processo cognitivo com maior propriedade. Só que, antes de organizá-las e dirigí-las, é necessário ter 
vontade de docentes conceber tais situações. Essa vontade, no entanto, pode sofrer influência das condições durante as buscas de recuperação de um espaço justo para realizar os procedimentos pedagógicos (PERRENOUD, 2000) que considerem, em primeiro lugar, as raízes do conhecimento dos aprendizes. Porém, ao encontrar meios de superação das adversidades em sala de aula há um estímulo às vontades transformandoas em disposição de colocar-se na perspectiva do aluno.

Criar e recriar situações de aprendizagem não é, nem de longe, reproduzir situações já existentes. Não é uma fórmula que se repete, pois cada turma, cada escola, cada comunidade em que estão inseridas possui uma dinâmica peculiar que requer apropriações e adequações de determinadas práticas pedagógicas à sua maneira. Desejando, assim, a contextualização das situações de aprendizagem, para que possam fluir entre os alunos interessados e, inclusive, resgatar os desinteressados. A contextualização dessas situações encarrega-se desse poder. Concebê-las, portanto, a partir do mundo experimentado das crianças, significa adotar uma competência docente preocupada com a representatividade ${ }^{6}$.

Diante dessa preocupação, o Ensino de Geografia busca implementar em sala de aula, por meio das práticas pedagógicas, também uma educação para a cidadania, pois:

"A Geografia tem grande importância na formação do cidadão, visto que seu objeto de estudo é o espaço. Este se constitui como político, cultural, social, como também físico. É, ao mesmo tempo, concreto e abstrato. É, enfim, dialético. Portanto o espaço geográfico pode/deve não apenas ser visto, como trabalhado como o lugar de vivência, aproximando-se portanto do aluno e de sua realidade." (BORGES et al., 2009, p.01)

Essa aproximação busca analisar o histórico das experiências dos alunos e agregar valores e sentidos sociais nas diferentes formas que relatam suas vivências no espaço (CALLAI, 2001). Compreendemos nos tópicos anteriores que desta forma encontramos acessos para trabalhar em cima dos relatos. Esse relatos são como ferramentas para abordar a realidade, porém como viabilizamos uma ocasião pedagógica confortável que os permitam dizer e manifestar-se espontaneamente? O que de fato poderia provocaria um maior envolvimento da prática na relação professor/aluno?

Apoiadas nas observações feitas na turma de $2^{\circ}$ ano do fundamental do CAp UERJ, sugerimos que seja antes de mais nada, até mesmo antes da criação das situações de aprendizagem, o compartilhamento e flexibilidade do planejamento diário de aula. A negociação do que se pretende ensinar e do que desejam aprender, pois como observado em campo, essa possibilidade coincide com que Perrenoud (2000) nos diz sobre "provocar uma paixão desinteressada pelo saber", porque a livre escolha coletiva de conteúdos e inclusive de metodologias não requer a necessidade de tentar justificá-las pelo caráter utilitário. Segundo ele, o envolvimento dos alunos com seu próprio ensino poderá promover uma cumplicidade na busca pelo conhecimento, permitindo-os se sentirem provedores de sua própria aprendizagem.

A Educação Ambiental e sua enorme gama de conceitos e conteúdos que perpassam em várias disciplinas curriculares assume um papel desafiador. E tratando-se neste artigo de uma pesquisa realizada no Ensino Fundamental I deparamo-nos com a potencialização desse desafio, principalmente no que se refere ao alcance de seus objetivos pelo Ensino de Geografia. Em Callai (2014), há um estudo que diz sobre a dificuldade de ensinar a geografia nos anos iniciais, a autora nos conta que essa dificuldade pode ser encontrada na tentativa de auxiliar os estudantes a compreender sua 
espacialidade, que segundo a ela, é cada vez mais complexa. Além de identificar os problemas de ordem epistemológica que aparecem neste nível de ensino, pois não depende somente da técnica e metodologia para delimitar os rumos do ensino/aprendizagem, precisa-se explorar os aportes teóricos imbricados com a prática.

Porém, para recorrer a esses aportes é necessário, na formação e ação docente da pedagogia e da licenciatura em geografia, o interesse em dialogar-se entre si na busca de resolver o problema epistêmico. A pedagogia, por sua vez, criando maiores condições para articular as informações geográficas na finalidade de analisar a sociedade pela materialização espacial dos fenômenos sociais (CALLAI, 2014). Mas o que debatemos aqui, por agora, não se trata essencialmente disto. $\mathrm{O}$ que consideramos pertinente discutir é como amenizar a dificuldade de auxiliar os alunos para a compreensão de suas espacialidades através da geografia com interesse no desenvolvimento de uma Educação Ambiental com propostas pedagógica centradas na capacitação de avaliação e participação dos alunos (JACOBI, 2003).

Retomando as contribuições de Perrenoud (2000), acreditamos que a criação e permissão de situações de aprendizagem seja o meio de promover a cumplicidade na busca do conhecimento e a partir disso incentivar a autonomia do aluno nas escolhas dos conteúdos em negociação com o professor. A participação das crianças, num sentido lógico, as retiram de posição passiva e através dela são desafiadas a exercitar escolhas e decisões democráticas sobre a própria aprendizagem, consequentemente, ajuda manter maior parte da turma interessada a explorar os conteúdos escolhidos.

Isso acontece porque o aluno apropria-se do conhecimento e consegue construir um vínculo com a sua realidade. Neste caso, o professor acessa potentes oportunidades de desenvolver suas competências docentes. Não apenas se limita em conceber as situações ou as deixam fluir sem intermediações entre as ações das crianças. Como por exemplo, o que escreve Jacobi (2003), sobre o educador ser um mediador na construção de referências ambientais na Educação Ambiental. Tendo a responsabilidade de saber identificar os retornos cognitivos dos alunos, pois deve preocupar-se em reconhecer os resultados, contornando as situações que eles mesmos ajudaram a construir, e seguir trabalhando com propostas que deem consequências. Por isso consideramos indispensável a importância da avaliação docente durante as atividades oriundas das situações de aprendizagem.

\section{O DESENHO E O RECONHECIMENTO DE ESPACIALIDADES}

Dentre as várias propostas pedagógicas existentes, a que nos referimos foi a elaboração de representações gráficas nas turmas dos anos iniciais como uma atividade consequente e grande aliada ao Ensino de Geografia. Pois, como vimos, além de sintetizar a realidade conceituada (PEREIRA, s.d.) da criança, pretende compreender as representações mentais, sociais e espaciais (PONTUSCHKA et al., 2007) desenhadas por elas. Configurando-se numa competente ferramenta metodológica que permite ao docente embarcar nas revelações das diferentes realidades identificadas.

Não basta identificar o nível de aprendizagem dos alunos pelas suas sínteses para compreender espacialidade na representação gráfica. É claro que também é preciso avaliar se conseguiram desenvolver cognitivamente a atividade conforme propositada ou não e se foram capazes de explorar suas habilidades nos aspectos intelectuais e estéticos ou não. Mas, o que está realmente em jogo é a necessidade que surge diante desses objetivos, a descoberta do que se esconde sob os desenhos mediante aos seus aspectos socioespaciais. Cabe ao professor somente a interpretação e ao aluno a 
representação? E se por acaso for algo além disso, como trabalhar em cima das descobertas?

Sabemos que o caminho inicial é a tomada de consciência do comprometimento das práticas com a realidade, porém reconhecemos que é uma longa jornada a busca de respostas que nos levem a superar os obstáculos para esse comprometimento. Apontamos, neste artigo, para uma produção do sentido sobre a Educação Ambiental. Entretanto, acreditamos que existam muitas outras direções de produzir sentidos sobre um determinado conhecimento. Os instrumentos de uma educação comprometida com a realidade, mencionados aqui, é apenas um exemplo de resgate contextualizador.

Em conjunto, a concepção das situações didáticas, o compartilhamento e flexibilidade do planejamento de aula, a negociação, o auxílio à compreensão da espacialidade do aluno, a atividade da representação gráfica e mais a identificação e avaliação docente, viabilizam a conectividade do mundo próximo do aluno e deslumbra o professor a trabalhar cada vez mais pela cidadania e representatividade em sala de aula. Promovendo, por sua vez, a justiça social desde o ambiente escolar. Pois, e agora em concordância com o projeto que favoreceu esta pesquisa, esse conjunto de ferramentas comporta a solidariedade, igualdade, respeito a diferença através das formas democrática, como bem disse Jacobi (2003), de aplicar o ensino/aprendizagem.

A cumplicidade da turma é compensatória, faz do trabalho docente entusiasmante e como causa, no desenrolar das atividades, as crianças aprendem com maior espontaneidade. Afinal, é uma prática que abandona o caminho burocrático na educação (CALLAI, 2001) e, pela contextualização, gera novas possibilidades de criar inéditas ocasiões de aprendizagem partindo do interesse dos próprios alunos (PERRENOUD, 2000).

\section{COMO O DESENHO SERVE AO AUXÍLIO À EDUCAÇÃO AMBIENTAL?}

Como amenizar a dificuldade do auxílio a espacialidade a partir das sínteses realizadas pelas crianças? Bom, vimos que há uma dinâmica muito complexa que nos permite ou não auxiliar a espacialidade dos alunos, por outro lado também fomos capazes de ver, ao longo do texto, que a complexidade não encontra-se somente na orientação ao aluno. Mas na própria prática do professor em ser competente o bastante em manejar atividades como a representação gráfica na escola. Percebemos que o desenho tem uma abordagem metodológica difícil de ser aplicada em sua minuciosidade.

Entretanto, uma discussão foi realizada acerca do que podemos objetivar através do desenho e do que o professor poderá utilizar para alcançar esses objetivos. Foram contribuições significantes na fundamentação metodológica da representação gráfica e que podem ajudar na formação docente não apenas do professor de Geografia, mas de vários outros profissionais da área da Educação interessados em aplicar uma perspectiva espacial sobre suas práticas. Incluindo operar objetivos da Educação Ambiental.

Querer compreender e aproximar o espaço vivido do aluno à escola acompanha a vontade - ou necessidade - de descobrir como ele poderá se sentir representado espacialmente durante as atividades escolares. É consequente. E utilizando-nos dos desenhos como fonte de dados da vida e experiência das crianças com relação ao lugar que vivem, devemos nos questionar: existe a possibilidade de amenizar a dificuldade da turma ao auxílio à Educação Ambiental através dos desenhos infantis?

Voltando à Perrenoud (2000), a concepção de situações didáticas deve aproveitar o interesse dos alunos. E nada como suas próprias produções para tornar-se ponto de partida de novas ocasiões que deem consequências as sínteses elaboradas pelas crianças. 
Transformá-las em novas propostas de aprendizagem é um saber docente que possibilita o prosseguimento didático das atividades iniciais e que constrói, gradativamente, a contextualização do espaço vivido das crianças pelas suas narrativas e representações. Enriquecendo as abordagens durantes as aulas e incluindo cada vez mais debates sobre o lugar e suas práticas sociais.

As funções desempenhadas pelas crianças no desenho resgatam referências do meio externo e as assimilações são realizadas durante sua produção. Desta forma, o professor precisa encarar as representações gráficas com uma relação conflitante entre a realidade material e a realidade conceituada. Que em algum momento breve precisará de uma intervenção. Não em sua produção propriamente dita, mas no conflito entre as realidades. E, assim, pensar intervir pela busca de uma interface que não despreze a objetividade e a subjetividade da representação.

As possibilidades extraídas das sínteses gráficas das crianças nos direcionam a montar novos esquemas didáticos que explorem a realidade apresentada graficamente por elas. Cria-se uma relação pedagógica entre os conhecimentos dos alunos e o do professor. Onde um não se sobrepõe ao outro, mas que podem ser integrados metodologicamente pela tríplice função de Callai (2001), representada pelo resgate do conhecimento produzido cientificamente, reconhecimento e valorização do conhecimento que cada criança carrega consigo e atribuição de um sentido social em ambos conhecimentos.

Quando recuperamos as significações dos desenhos infantis e nos deparamos com o conflito entre a realidade material e a conceituada devemos nos preocupar com a interseção entre uma e outra a fim de não esvaziar a atividade proposta. E encontramos nas contribuições de Callai (2001) três formas de conduzir os conteúdos trabalhados ao comprometimento com a realidade pela perspectiva espacial. Primeiro é o conhecimento científico sendo resgatado para entender e explicar o lugar, os fenômenos e os processos espaciais sem desconsiderar ou desprezar o conhecimento prévio do aluno.

Esse conhecimento prévio é construído pela criança através do desenvolvimento intelectual do lugar, desde as primeiras relações espaciais sofridas. Conhecimento composto de memórias que precisam ser valorizadas pelo docente para que possa ter fundamentação didática para auxiliar a espacialidade do aluno promovendo uma educação para a cidadania democrática além de trabalhar a representatividade do indivíduo em relação ao espaço vivido. Essas duas últimas intrinsecamente relacionada com a atribuição social que fica sob a responsabilidade do professor durante as atividades, inclusive as que utiliza-se do desenho para elucidar conceitos e conteúdos que abordem a realidade.

\section{CONSIDERAÇÕES FINAIS}

Diante da leitura, nos demos conta de que esta pesquisa teve origem nas práticas que despretensiosamente abordou conteúdos da geografia pela necessidade de transversalizar a Educação Ambiental. E que arrumou o terreno para uma excelente oportunidade de dialogar o Ensino de Geografia com a Pedagogia dos anos iniciais numa relação mais próxima. Com isso, fomentou a busca de tentar vincular as práticas pedagógicas em sala de aula com o espaço vivido dos alunos através da representação gráfica.

A importância da contextualização foi destaque durante todo o trabalho, pois sem o comprometimento da educação escolar com a realidade dos alunos alguns fundamentos didáticos não seriam possíveis para objetivar o envolvimento das crianças com o ensino. Foi defendido que para estudar o "lugar" é preciso colher o histórico das 
experiências dos alunos e para que isso ocorra é necessário considerá-los protagonistas em sala de aula. Ou seja, provedores de sua própria aprendizagem. Isto é, em cumplicidade e negociação com o professor.

Vimos que essa negociação de escolher democraticamente o que se aprende possibilita enormes situações espontâneas de aprendizagens e também permite o professor optar por diferentes formas de elucidar os conceitos e conteúdos trabalhados, inclusive o direito ao acesso à Educação Ambiental. E dentre essas diferentes formas, adentramos na elucidação através da representação gráfica. Admitimos o desenho como ferramenta metodológica que cumpre a função de aproximar o espaço vivido das crianças à escola. Além de recurso visual que nos faz reconhecer espacialidades representadas.

Apesar de remeter-se quase sempre à cartografia, a representação gráfica no Ensino de Geografia pode ser de outra modalidade, como os desenhos livre nos anos iniciais. Mas que também, assim como os mapas cumprem o papel da comunicação espacial e sintetiza, pelas assimilações do "lugar" pela "paisagem" e o conhecimento e noções espaciais apreendidas. Foi o que podemos observar e registrar na turma do $2^{\circ}$ ano do Ensino Fundamental I do CAp UERJ, através do projeto "Constituir Saberes Didáticos para Lidar com a Diferença na Escola".

Que pela realização da atividade com os desenhos ocasionada pelos interesses dos alunos, veio a ser um importante material de investigação para abordagens metodológicas, capacitação de interpretação na formação docente e consequência para outras situações didáticas para a educação à cidadania democrática, representatividade e auxílio à espacialidade. O resgate da significação infantil e a análise das imagens produzidas pelas crianças tornando-se novas ocasiões para trabalhar os aspectos das diferenças socioespaciais apontados por elas nas representações gráficas.

Assim, descobrindo que o desenho vai muito além das operações cognitivas, habilidades intelectuais ou estéticas. Ele pode ser capaz de revelar o espaço vivido dos alunos, como eles se reconhecem no lugar e quais as aproximações possíveis para comprometer a educação com a realidade de cada um. Trata-se de criar e recriar situações de aprendizagem contextualizadas com os dados revelados e interpretados através dos desenhos. Por esse motivo, de ser consequente, atividades como a representação gráfica precisam ser exploradas e dadas com importância nos anos iniciais, pois são aliadas as falas das crianças e complementam suas manifestações revelando o não dito.

\section{NOTAS}

1 - Refere-se ao processo de aquisição conhecimento por algumas funções mentais na primeira infância. Ver: PIAGET, Jean. Seis Estudos de Psicologia. Tradução: Maria Alice Magalhães D’Amorim e Paulo Sérgio Lima Silva. 25ª ed. Rio de Janeiro: Forense Universitária, 2011. p. 24 - 40.

2 - Articular temas transversais considerando as concepções teóricas e metodológicas da Geografia, priorizando um olhar específico da área. Conforme descrito nos Parâmetros Curriculares Nacionais, 1997. p. 42.

3 - Recomendo a leitura: CARLOS, Ana Fani Alessandri. Definir o Lugar? In: CARLOS, Ana Fani Alessandri (Org.). O Lugar No/Do Mundo. 2007. p. 17 - 20.

4 - Interação fundamental entre fatores internos e externos do meio (PIAGET, 2011:89).

5 - BRASIL, Ministério da Educação. Parâmetros Curriculares Nacionais: $1^{a}$ a $4^{a}$ série. História e Geografia. Brasília: MEC, Sec. de Educação Fundamental, 1997. p. 89. 
6 - No que tange às considerações de Ivanise Miranda sobre a importância teórica e metodológica de contextualizar o indivíduo, sob abordagem sócio-histórica em Considerações sobre o indivíduo representativo, 1993. p. 53.

7 - BORGES, V. J. et al. A geografia escolar e a formação para a cidadania, 2009. p. 01.

\section{REFERÊNCIA BIBLIOGRÁFICA}

ALARCÃO, Isabel. Professor-investigador: Que sentido? Que formação? Cadernos de Formação de Professores, N 1, pp. 21-30. Aveiro, 2001.

BRASIL, Ministério da Educação. Parâmetros Curriculares Nacionais: $1^{a}$ a $4^{a}$ série. História e Geografia. Brasília: MEC, Sec. de Educação Fundamental, 1997.

BORGES, Vilmar José et al. A Geografia Escolar e a Formação para a Cidadania: Teoria e Prática de Professores dos Municípios da Grande Vitória - ES, Brasil. In: Encontro De Geógrafos Da América Latina, 12., 2009, v. 12, p. 1 - 14. Disponível em: $<$ http://observatoriogeograficoamericalatina.org.mx/egal12/Ensenanzadelageografia/Inv estigacionydesarrolloeducativo/71.pdf $>$.

CALlAI, Helena Copetti. A Geografia e a Escola: Muda a Geografia? Muda o Ensino?. Terra Livre, São Paulo, n. 16, p.133-152, $1^{\circ}$ Semestre, 2001.

CALLAI, Helena Copetti. A Geografia é Ensinada nos Anos Iniciais? Aprende-se Geografia nos Anos Iniciais? In: TONINI, Ivaine Maria et al (Org.). Ensino de Geografia e suas Composições Curriculares. São Paulo: Mediação, 2014. Cap. 3. p. 3141.

CARLOS, Ana Fani Alessandri (Org.). Definir o Lugar? In: CARLOS, Ana Fani Alessandri (Org.). O Lugar No/Do Mundo. São Paulo: FFLCH, 2007. Cap. 1. p. 17-20.

JACOBI, Pedro. Educação Ambiental, Cidadania E Sustentabilidade. Cadernos de Pesquisa, São Paulo, v. 118, p.189-205, mar. 2003.

LEMOS, Enilda Maria; DAVID, Célia Maria. Reflexões sobre o tema transversal meio ambiente no ensino fundamental. Camine: Caminhos da Educação, Franca, v. 3, n. 1, p.01-18, set. 2011.

OLIVEIRA, Lívia de. Estudo Metodológico e Cognitivo do Mapa. In: ALMEIDA, Rosângela Doin de (Org.). Cartografia Escolar. 2. ed. São Paulo: Contexto, 2014. Cap.1. p. 15-40.

OLIVEIRA JUNIOR, Wenceslao Machado. Desenhos e Escutas. In: NUNES, Flaviana Gasparotti (Org.). Ensino de Geografia: Novos Olhares e Práticas. Dourados: UFGD, 2011. Cap. 1. p. 13-36.

PEREIRA, Laïs, O desenho infantil e a construção da significação: um estudo de caso. Disponível em:

<http://portal.unesco.org/culture/en/files/29712/11376608891lais-kruckenpereira.pdf/lais-krucken-pereira.pdf $>$. 
PERRENOUD, Philippe, Organizar e dirigir situações de aprendizagem. In Dez novas competências para ensinar. Ed. Artmed. Porto Alegre, 2000.

PIAGET, Jean. Seis Estudos de Psicologia. Tradução: Maria Alice Magalhães D’Amorim e Paulo Sérgio Lima Silva. 25 a ed. Rio de Janeiro: Forense Universitária, 2011.

PONTUSCHKA, Nídia. PAGANELLI, Tomoko. CACETE, Núria. Representações gráficas na Geografia. In Para ensinar e aprender Geografia $1^{\mathrm{a}}$ ed, Ed. Cortez, São Paulo, p. 291- 317, 2007.

SENE, José Eustáquio de. A Educação Ambiental como tema transversal no Ensino de Geografia: possibilidades e limites. Revista Geográfica de América Central, Costa Rica, v. , p.01-12, 2011. 